\title{
Diffusion and surface alloying of gradient nanostructured metals
}

\author{
Zhenbo Wang* and Ke Lu
}

\author{
Review \\ Address: \\ Shenyang National Laboratory for Materials Science, Institute of Metal \\ Research, Chinese Academy of Sciences, 72 Wenhua Road, \\ Shenyang 110016, China \\ Email: \\ Zhenbo Wang* - zbwang@imr.ac.cn \\ ${ }^{*}$ Corresponding author \\ Keywords: \\ diffusion; gradient nanostructures; grain boundary; interface; surface \\ alloying
}

Beilstein J. Nanotechnol. 2017, 8, 547-560.

doi:10.3762/bjnano.8.59

Received: 01 November 2016

Accepted: 03 February 2017

Published: 03 March 2017

This article is part of the Thematic Series "Advances in nanomaterials II".

Guest Editor: H. Hahn

(c) 2017 Wang and Lu; licensee Beilstein-Institut. License and terms: see end of document.

\begin{abstract}
Gradient nanostructures (GNSs) have been optimized in recent years for desired performance. The diffusion behavior in GNS metals is crucial for understanding the diffusion mechanism and relative characteristics of different interfaces that provide fundamental understanding for advancing the traditional surface alloying processes. In this paper, atomic diffusion, reactive diffusion, and surface alloying processes are reviewed for various metals with a preformed GNS surface layer. We emphasize the promoted atomic diffusion and reactive diffusion in the GNS surface layer that are related to a higher interfacial energy state with respect to those in relaxed coarse-grained samples. Accordingly, different surface alloying processes, such as nitriding and chromizing, have been modified significantly, and some diffusion-related properties have been enhanced. Finally, the perspectives on current research in this field are discussed.
\end{abstract}

\section{Introduction}

A gradient nanostructure is a unique architecture in which a layer of nanoscale-grained structure adheres to a ductile coarsegrained (CG) substrate of the same material; a transition layer with graded grain sizes is positioned between them. This architecture with a graded spatial variation of grain sizes offers a number of unique opportunities to enhance the properties of materials. It enables the delocalization of strains in the nanograined structures, resulting in plastic deformation behavior fundamentally different from that of the free-standing homogeneous nano-grained and CG samples. For example, a consider- able tensile ductility was achieved with the significantly enhanced strength in different metals with a gradient nanostructured (GNS) layer [1-3], distinct from the traditional trade-offs between strength and ductility in conventional metals and alloys. In addition, GNS materials exhibit significantly enhanced wear resistance and fatigue resistance compared with their nano-grained and CG counterparts [4-7].

Investigating the diffusion behavior of GNS materials is an important topic mostly due to the following reasons: 
1. Numerous interfaces in the nanostructured layer make it possible to study interfacial diffusion and relative characteristics, such as interfacial structure, precipitation, phase transformation, plastic deformation, and chemical reaction, at lower temperatures. In comparison, it is difficult to obtain enough information on these aspects particularly on the $C$-type diffusion regime as laid out in [8] - because of an insufficient number of interfaces in CG materials.

2. A graded variation of interface types may accompany the graded distribution of grain sizes in a GNS layer. Such a microstructure provides a unique sample to study the effects of grain size and interface type on diffusion properties.

3. Atomic diffusion is the essential factor in surface alloying processes (such as nitriding and chromizing), and diffusion studies in GNS materials provide insights for modifying traditional surface alloying processes of engineering metallic materials.

GNSs have been generated on various metals by methods with controlled surface plastic deformation [9-11]. In this paper, recent progress in the diffusion studies in GNS metals will be clarified to understand diffusion fundamentals and relationships between microstructure and diffusion in nanostructured materials, followed by some typical applications of GNS on advancing traditional surface alloying processes.

\section{Review \\ Interfacial diffusion in GNS materials}

In the $1980 \mathrm{~s}$, Gleiter et al. [12,13] successfully synthesized the first nanostructured metallic sample by means of inert gas condensation and consolidation (IGC). Since then, studies have been performed to reveal the diffusion behavior of nanostructured metals worldwide. However, the measured results were rather scattered and even controversial. For instance, markedly promoted diffusion coefficients with a lower activation enthalpy were measured in the nanostructured $\mathrm{Cu}$ synthesized by IGC [14-16]. And a comparable diffusivity with that of conventional grain boundaries (GBs) was revealed in a nanostructured $\gamma-\mathrm{Fe}-\mathrm{Ni}$ alloy prepared by ball milling with subsequent sintering (BMS), while inter-agglomerate boundaries showed much faster diffusion rates $(\approx 4$ orders of magnitude higher) with a lower activation enthalpy than the GB diffusion [17]. Moreover, interfacial diffusion coefficients in an $\mathrm{Fe}_{3} \mathrm{Si}$ nanocomposite produced by crystallization (CRY) from a melt-spun amorphous sample were revealed to be even lower in comparison with those in the CG sample [18].

Particular attention has been paid to the diffusion behavior in nanostructured or ultrafine grained (UFG) materials produced by using severe plastic deformation (SPD), mostly because of the bulk forms of nanostructures. Inconsistences also exist in the experimental results. For example, Würschum et al. [19] found that diffusivities in a SPD Pd sample are similar to those in conventional GBs. However, Kolobov et al. [20] detected an increment of $10^{4}-10^{5}$ in GB diffusivities (with lower activation enthalpy) of $\mathrm{Cu}$ in a SPD Ni sample in comparison with those in a CG sample. The diffusion coefficients along some ultra-fast channels (together with some conventional GBs) in an UFG $\mathrm{Cu}-\mathrm{Zr}$ alloy sample prepared via SPD were found to be $\approx 10^{3}$ times higher than those along GBs in a high-purity $\mathrm{CG} \mathrm{Cu}$ sample [21]. In order to differentiate these ultra-fast diffusion channels from conventional GBs, the term "nonequilibrium" GBs was used. In this case, GBs might gather a large number of irregular (extrinsic) dislocation structures, so that extra free energy might be introduced in the interfaces, while misorientations across them remain stable [22,23]. The existence of nonequilibrium GBs after SPD processing has been supported by strain mapping results in a SPD Pd-Ag alloy, in which the GB thickness (with evident strain) is determined to be $\approx 1.5 \mathrm{~nm}$ and is markedly larger than the thickness of relaxed GBs $(\approx 0.5 \mathrm{~nm})$ [24]. In addition, the higher energy of nonequilibrium GBs as compared to conventional GBs has been demonstrated by the transformation of partial to complete GB wetting in $\mathrm{Sn}-\mathrm{Pb}$ alloys during continuous strain by Straumal et al. [25]. However, this notion was confused by two works in the SPD Cu and $\mathrm{Cu}-\mathrm{Pb}$ alloy [26,27], in which various defects such as vacancy agglomerations, nanometer- and micrometer-sized voids were observed. These defects might be linked and significantly accelerate atomic penetration in the materials. In addition, the concurrent influence from lattice diffusion might not be completely excluded from the mean diffusion flux in SPD metals, in which the grain sizes are usually in the submicrometer scale $(>200 \mathrm{~nm})$ and numerous dislocations exist in grains [28].

The microstructural observations revealed that the GNS layers on metals processed by surface mechanical attrition treatments (SMAT) are porosity-free, and the mean grain sizes are on the nanoscale $(<100 \mathrm{~nm})$ in the surface layers with a thickness of tens of micrometers, for example on pure $\mathrm{Fe}$ [29] and $\mathrm{Cu}$ [30]. In addition, a graded distribution of interfacial structure was obtained in the GNS surface layer of $\mathrm{Cu}$ [30], with interfaces sequentially dominated by twin boundaries (TBs), high-angle GBs (HAGBs), low-angle GBs (LAGBs) and dislocation walls with an increasing depth. These microstructures characteristics provided unique opportunities to study the relationship between the diffusion property and microstructure into the nanometer scale. The diffusion studies in these materials will be reviewed and compared with results from other nanostructured metals in this section. 


\section{Diffusion behavior in nanostructured surface layers}

The diffusion properties of $\mathrm{Cr}$ in GNS Fe were measured within the temperature range of $300-380{ }^{\circ} \mathrm{C}$ on a SMAT Fe sample with a mean grain size of $\approx 10 \mathrm{~nm}$ in the top surface layer electroplated with a thin layer of $\mathrm{Cr}$ [31]. The apparent diffusivity of $\mathrm{Cr}$ in the GNS Fe is 7-9 orders of magnitude higher than that in the Fe lattice and 4-5 orders of magnitude higher than that along GBs of ferrite, as shown in Figure 1. In terms of the diffusion kinetics with Arrhenius dependence in the concerned temperature range, the pre-exponential factor and the activation enthalpy of $\mathrm{Cr}$ diffusion in the nanostructured $\mathrm{Fe}$ were calculated. It is seen that the pre-exponential factor of $\mathrm{Cr}$ diffusion in nanostructured $\mathrm{Fe}$ is much higher than that for conventional GB diffusion in $\alpha-\mathrm{Fe}$, and the diffusion activation enthalpy is slightly lower than that that of GB diffusion.

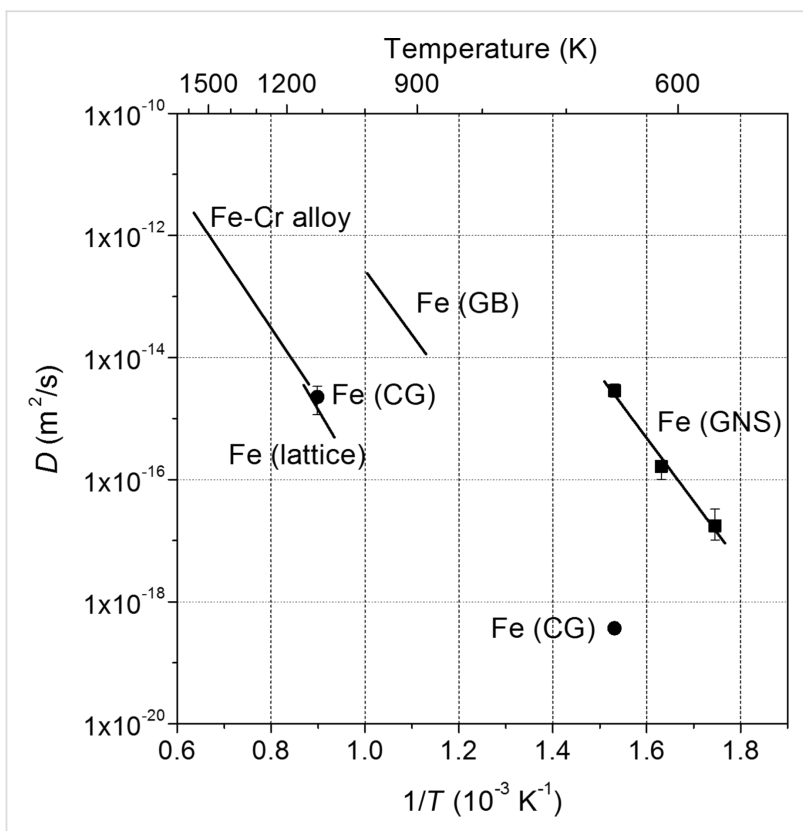

Figure 1: Temperature dependence of the diffusion coefficients of $\mathrm{Cr}$ in the GNS Fe produced by SMAT and in the CG Fe, in comparison with those for the $\alpha-F e$ lattice diffusion, the $\alpha-F e ~ G B$ diffusion and the diffusion in Fe-Cr alloy. Figure reproduced with permission from [31], copyright 2003 Elsevier.

In addition, the Cr-diffusion depth values were determined in GNS low carbon steel samples chromized in a packed powder mixture of $\mathrm{Cr}-\mathrm{NH}_{4} \mathrm{Cl}-\mathrm{Al}_{2} \mathrm{O}_{3}$, as shown in Figure 2 [32]. One can see that the diffusion depth into the as-SMAT sample was larger than that into the CG sample after the same chromizing treatment within the temperature range of $400-860{ }^{\circ} \mathrm{C}$. The ratio of the value into the as-SMAT sample relative to the value into the CG sample decreased with elevating temperatures. A similar trend has also been observed in a GNS H13 steel sample, in which a significantly increased $\mathrm{Cr}$-diffusion depth with respect to that in the $\mathrm{CG}$ sample was achieved at chromizing temperatures below $600{ }^{\circ} \mathrm{C}$, and the depth even decreased with increasing temperatures above $600{ }^{\circ} \mathrm{C}$ [33]. Meanwhile, it was noticed that an isothermal preannealing might decrease the Cr-diffusion depth. For example, the pre-annealing at $400{ }^{\circ} \mathrm{C}$ decreased the Cr-diffusion depth values to $\approx 60 \%$ of the as-prepared GNS low carbon steel (also see Figure 2).

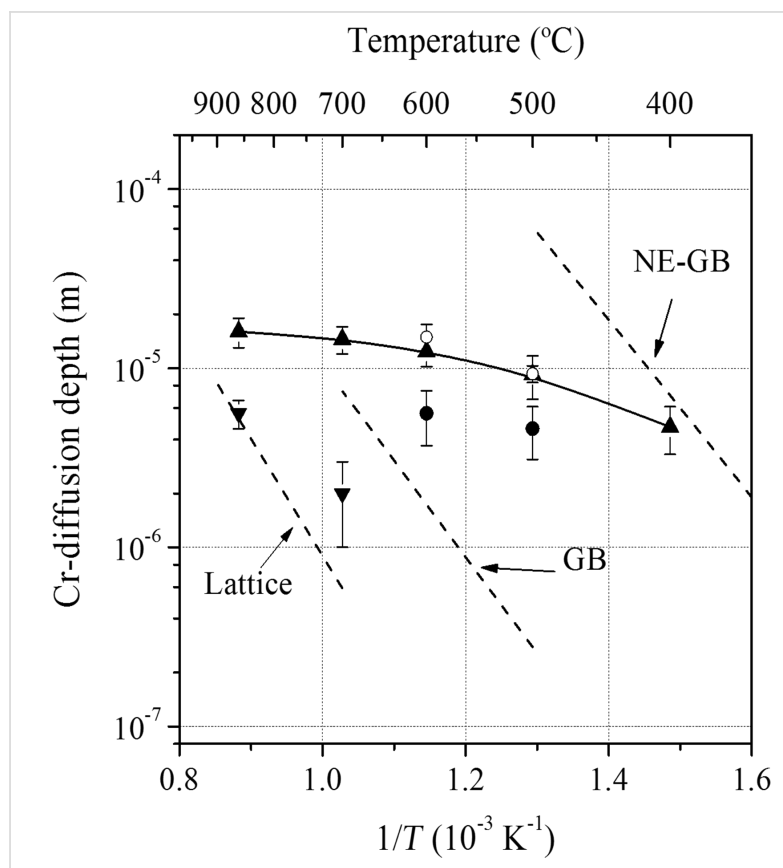

Figure 2: Variations of Cr-diffusion depth with temperature in different low carbon steel samples: as-SMAT $(\boldsymbol{\Delta}), \mathrm{CG}(\boldsymbol{\nabla})$, SMAT with subsequent annealing at $300^{\circ} \mathrm{C}(\circ)$ and $400{ }^{\circ} \mathrm{C}(\bullet)$ for $180 \mathrm{~min}$. In comparison, the calculation results in terms of the lattice diffusion [34], the conventional GB diffusion (GB) [35], and the diffusion in GNS Fe (NE$\mathrm{GB}$ [ [31] were also included. Figure reproduced with permission from [32], copyright 2005 Elsevier.

Since the surface $\mathrm{Cr}$ concentration is approximately constant during chromizing, the apparent diffusivity in the GNS surface layer $\left(D_{\mathrm{GNS}}\right)$ can be calculated from the measured Cr-diffusion depth $(x)$ from

$$
D_{\mathrm{GNS}}=x^{2} / \alpha t
$$

where $\alpha$ is a constant and $t$ is the chromizing duration [36]. The results show that $D_{\mathrm{GNS}}$ is about $8.5 \times 10^{3}$ times higher than the diffusivity along GBs in the CG low carbon steel sample ( $D_{\mathrm{RGB}}$ ) at $400{ }^{\circ} \mathrm{C}$, and the ratio of $D_{\mathrm{GNS}}$ to $D_{\mathrm{RGB}}$ decreases gradually with increasing temperature. While evident grain growth occurred in the nanostructured surface layer, the ratio of $D_{\mathrm{GNS}}$ to $D_{\mathrm{RGB}}$ is even less than 1 . After the preannealing treatment at $400{ }^{\circ} \mathrm{C}, D_{\mathrm{GNS}}$ decreases to $\approx 1 / 4$ of that in the as-prepared sample. 
Comparing the diffusion studies in GNS surface layers prepared by SMAT with the results in other nanostructured or UFG metals, as in Table 1, we may conclude:

1) The measured interfacial diffusivity is sensitive to the sample preparation method. Diffusivities in nanostructured samples produced by using SMAT or SPD reach a value of $10^{3}-10^{5}$ times higher than those for GBs in CG samples. The diffusivity increment is typically within $10^{2}-10^{4}$ in nanostructured metals produced via the IGC or BMS techniques. Additionally, the interfacial diffusivity in nanostructured samples produced via CRY is much lower than that along GBs in the CG form. Meanwhile, the interfacial diffusivities in nanostructured metals in the as-prepared states decrease significantly after preannealing treatments during which GBs may be relaxed, especially when evident grain growth has occurred.

2) The diffusion activation enthalpies in nanostructured metals are typically $0.5-0.9$ of those along GBs in CG samples when no distinct relaxation or grain growth occurs. Additional-

Table 1: Diffusion studies in nanostructured metals prepared by different techniques.

\begin{tabular}{|c|c|c|c|c|c|c|c|}
\hline \multirow{2}{*}{$\begin{array}{l}\text { Material } \\
\text { (diffusant) }\end{array}$} & \multirow{2}{*}{$\begin{array}{l}\text { Grain size } \\
(\mathrm{nm})\end{array}$} & \multirow{2}{*}{$\begin{array}{l}\text { Preparation } \\
\text { method }^{a}\end{array}$} & \multirow{2}{*}{$\begin{array}{l}\text { Diffusion } \\
\text { temperature }\left({ }^{\circ} \mathrm{C}\right)\end{array}$} & \multirow[t]{2}{*}{$D_{\mathrm{NS}} / D_{\mathrm{RGB}}{ }^{\mathrm{b}}$} & \multicolumn{2}{|c|}{ Arrhenius parameters ${ }^{C}$} & \multirow[t]{2}{*}{ Ref. } \\
\hline & & & & & $D_{\mathrm{NS}}^{0} / D_{\mathrm{RGB}}^{0}$ & $Q_{N S} / Q_{R G B}$ & \\
\hline $\mathrm{Fe}(\mathrm{Cr})$ & $10-25$ & SMAT & $\begin{array}{l}300 \\
340 \\
380\end{array}$ & $\begin{array}{l}2.0 \times 10^{4} \\
9.4 \times 10^{3} \\
1.2 \times 10^{4}\end{array}$ & $7 \times 10^{2}$ & 0.9 & [31] \\
\hline Low-C-steel (Cr) & $10-30$ & SMAT & $\begin{array}{l}400 \\
500 \\
600 \\
700\end{array}$ & $\begin{array}{l}8.5 \times 10^{3} \\
2.1 \times 10^{2} \\
7.9^{*} \\
0.49^{*}\end{array}$ & NA & NA & [32] \\
\hline Low-C-steel (Cr) & 10-30 & $\mathrm{SMAT}+\mathrm{PA}$ & $\begin{array}{l}500 \\
600\end{array}$ & $\begin{array}{l}53 \\
1.6^{*}\end{array}$ & NA & NA & {$[32]$} \\
\hline H13-steel (Cr) & $10-30$ & SMAT & $\begin{array}{l}550 \\
600 \\
650\end{array}$ & $\begin{array}{l}17 \\
11^{*} \\
0.28^{*}\end{array}$ & NA & NA & [33] \\
\hline $\mathrm{Cu}(\mathrm{Ni})$ & 100 & SMAT & 130 & $1.1 \times 10^{4}$ & NA & NA & [38] \\
\hline $\mathrm{Ni}(\mathrm{Cu})$ & 300 & ECAP & $\begin{array}{l}125 \\
175\end{array}$ & $\begin{array}{l}1.1 \times 10^{5} \\
1.0 \times 10^{4}\end{array}$ & $4.4 \times 10^{-11}$ & 0.34 & {$[20]$} \\
\hline $\mathrm{Pd}(\mathrm{Fe})$ & $80-150$ & SPD & $\begin{array}{l}98 \\
200 \\
300\end{array}$ & $\begin{array}{l}3.0 \times 10^{3} \\
11^{*} \\
0.12^{\star}\end{array}$ & NA & NA & [19] \\
\hline $\mathrm{Cu}-\mathrm{Zr}(\mathrm{Ni})$ & 300 & ECAP & $151-280$ & $\begin{array}{l}0.7-1.4^{*} \\
(0.2-1.3) \times 10^{3}\end{array}$ & $\begin{array}{l}0.2 \\
2.3 \times 10^{3}\end{array}$ & $\begin{array}{l}0.93^{\mathrm{s}-\mathrm{GB}} \\
1.06^{\mathrm{f}-\mathrm{GB}}\end{array}$ & {$[21]$} \\
\hline $\mathrm{Cu}(\mathrm{Ni})$ & 300 & ECAP & $151-201$ & $0.5-1.5^{*}$ & 0.24 & 0.94 & [39] \\
\hline $\mathrm{Ni}(\mathrm{Ni})$ & 300 & ECAP & $\begin{array}{l}58-127 \\
167-227\end{array}$ & $\begin{array}{l}(0.7-28) \times 10^{5} \\
(0.2-4.5) \times 10^{3}\end{array}$ & $6.8 \times 10^{-4}$ & 0.52 & {$[40]$} \\
\hline $\mathrm{Cu}(\mathrm{Cu})$ & 8 & IGC & 120 & $1.1 \times 10^{2}$ & $3 \times 10^{-4}$ & 0.59 & {$[14,41]$} \\
\hline $\mathrm{Cu}(\mathrm{Ag})$ & 8 & IGC & $\begin{array}{l}30-70 \\
80-100\end{array}$ & $\begin{array}{l}\approx 2.3 \times 10^{3} \\
\approx 4.9 \times 10^{2}\end{array}$ & $\begin{array}{l}5.9 \times 10^{-3} \\
1.8 \times 10^{2}\end{array}$ & $\begin{array}{l}0.53 \\
0.86\end{array}$ & {$[15]$} \\
\hline $\mathrm{Cu}(\mathrm{Au})$ & 10 & IGC & 100 & $1.85 \times 10^{4}$ & NA & NA & [16] \\
\hline $\mathrm{Pd}(\mathrm{Fe})$ & 20 & IGC & $\begin{array}{l}200 \\
250\end{array}$ & $\begin{array}{l}7^{*} \\
0.7^{*}\end{array}$ & NA & NA & {$[19]$} \\
\hline $\mathrm{Cu}(\mathrm{Zn})$ & 120 & DPD & $\begin{array}{l}85-100 \\
115-190\end{array}$ & $\begin{array}{l}11 \\
0.05-3.5^{\star}\end{array}$ & NA & NA & {$[42]$} \\
\hline V-FeNi (Ag) & 100 & BMS & $411-547$ & $\begin{array}{l}\approx 1 \\
(0.34-3.7) \times 10^{4}\end{array}$ & $\begin{array}{l}\approx 1 \\
2 \times 10^{-3}\end{array}$ & $\begin{array}{l}\approx 1 \\
0.53 \mathrm{Al}\end{array}$ & [17] \\
\hline $\mathrm{Fe}_{3} \mathrm{Si}(\mathrm{Fe})$ & 12 & CRY & $380-420$ & $\approx 4 \times 10^{-5}$ & NA & $1.12^{\mathrm{a}-\mathrm{IF}}$ & [18] \\
\hline
\end{tabular}

aVarious preparation methods: SMAT+PA denotes SMAT with subsequent preannealing at $400{ }^{\circ} \mathrm{C}$, when no evident grain growth occurs but microstrain decreases markedly [32]. Equal channel angular pressing (ECAP) is a representative SPD method. DPD denotes the dynamic plastic deformation technique. Other abbreviations are referred to in the main text. ${ }^{b}$ Asterisked values indicate samples with remarkable grain growth during the concerned diffusion annealing. The thickness of GB $(\delta)$ was taken as $0.5 \mathrm{~nm}$ to calculate $D_{\mathrm{RGB}}$ when a triple product $s \delta D_{\mathrm{RGB}}$ was reported. ${ }^{\mathrm{c}}$ Arrhenius parameters: $D_{\mathrm{NS}}^{0}$ and $D_{\mathrm{RGB}}^{0}$ denote the apparent pre-exponential factors for diffusion along interfaces in a nanostructured metal and the relaxed CG sample, respectively; $Q_{N S}$ and $Q_{R G B}$ denote the diffusion activation enthalpies along interfaces in the nanostructured metal and the relaxed CG sample, respectively; The superscripts s-GB and f-GB denote "slow GB" and "fast GB", respectively, in [21]; Al denotes agglomerate interfaces, along which the diffusivity $\left(D_{\mathrm{a}}\right)$ was derived from a relationship with the product $\left(P_{\mathrm{a}}\right)$ as $P_{\mathrm{a}}=s_{\mathrm{a}} \cdot \delta_{\mathrm{a}} \cdot D_{\mathrm{a}} / \lambda($ referring to [17]); a-IF denotes amorphous interfaces in the nanocrystalline $\mathrm{Fe}_{3} \mathrm{Si}$ prepared by CRY [18]. 
ly, no dependence on the preparation method or grain size is indicated.

3) The effect of grain size on diffusivity seems to be rather weak within the scale regime from 10 to $300 \mathrm{~nm}$. Therefore, the contribution from triple junctions, of which the amount increases with decreased grain size and the diffusivity should be further enhanced due to the larger excess volume [31,37], might be insignificant within the present grain size scale.

This evidence suggests that GBs in the GNS layers are associated with a higher stored energy and/or with a higher density of defects compared to the GBs in conventional CG counterparts. According to the vacancy mechanism of GB diffusion $[43,44]$, they may facilitate diffusion by decreasing the vacancy formation energy. For example, the existence of a large fraction of free volume in the GNS layer has been demonstrated by the high intensities of the short- and middle-lifetime components in the results of positron annihilation spectroscopy measurements of the surface layer of the SMAT Fe [45].

While GB defects (i.e., extrinsic GB dislocations) are difficult to be identified in GNS or SPD metals, it is argued that the GB diffusion might also be accelerated by GB thickening, resulting from either the GB prewetting (premelting) or the pseudopartial GB wetting during sample preparation [46-49]. For example, a Zn-rich wetting layer of 2-10 $\mathrm{nm}$ in thickness has been formed along $\mathrm{Al} / \mathrm{Al}$ GBs in UFG Al-Zn alloys after high pressure torsion at room temperature [47]. Dramatically enhanced $\mathrm{GB}$ diffusivities were observed in $\mathrm{Cu}-\mathrm{Bi}$ and $\mathrm{Fe}-\mathrm{Si}-\mathrm{Zn}$ alloys with prewetted GBs $[48,49]$. Nevertheless, this notion might safely be excluded from the issues accelerating diffusion in the GNS layers, because no system (see Table 1) contains components which are inclined to form GB complexions connected with GB prewetting or pseudo-partial wetting $[46,50]$.

\section{Diffusion kinetics and free energy of different interfaces}

As illustrated in Figure 3a, the grain size increases and interface structure is sequentially dominated by TBs (or TB-like interfaces), HAGBs, LAGBs and dislocation walls with increasing depth in the GNS surface layer on a SMAT pure $\mathrm{Cu}$ sample $[30,38]$. Similar to the accelerated diffusion of $\mathrm{Cr}$ observed in GNS Fe and steels, a remarkable penetration of $\mathrm{Ni}$ into the GNS surface layer of the SMAT $\mathrm{Cu}$ has been detected at temperatures below $150^{\circ} \mathrm{C}[38,51,52]$. The effective diffusivity in the top surface layer is $\approx 3$ orders of magnitude higher than that along relaxed HAGBs in the annealed CG sample at $130{ }^{\circ} \mathrm{C}$. Furthermore, it is noticed that the effective diffusivity in the subsurface layer is higher than that in the top surface layer, and increases with increasing depth up to $30-50 \mu \mathrm{m}$, as shown in
Figure 3 b. After the diffusivity reaches a maximum value of $\approx 4$ orders of magnitude higher than that along the conventional HAGBs, it decreases with further increasing depth.
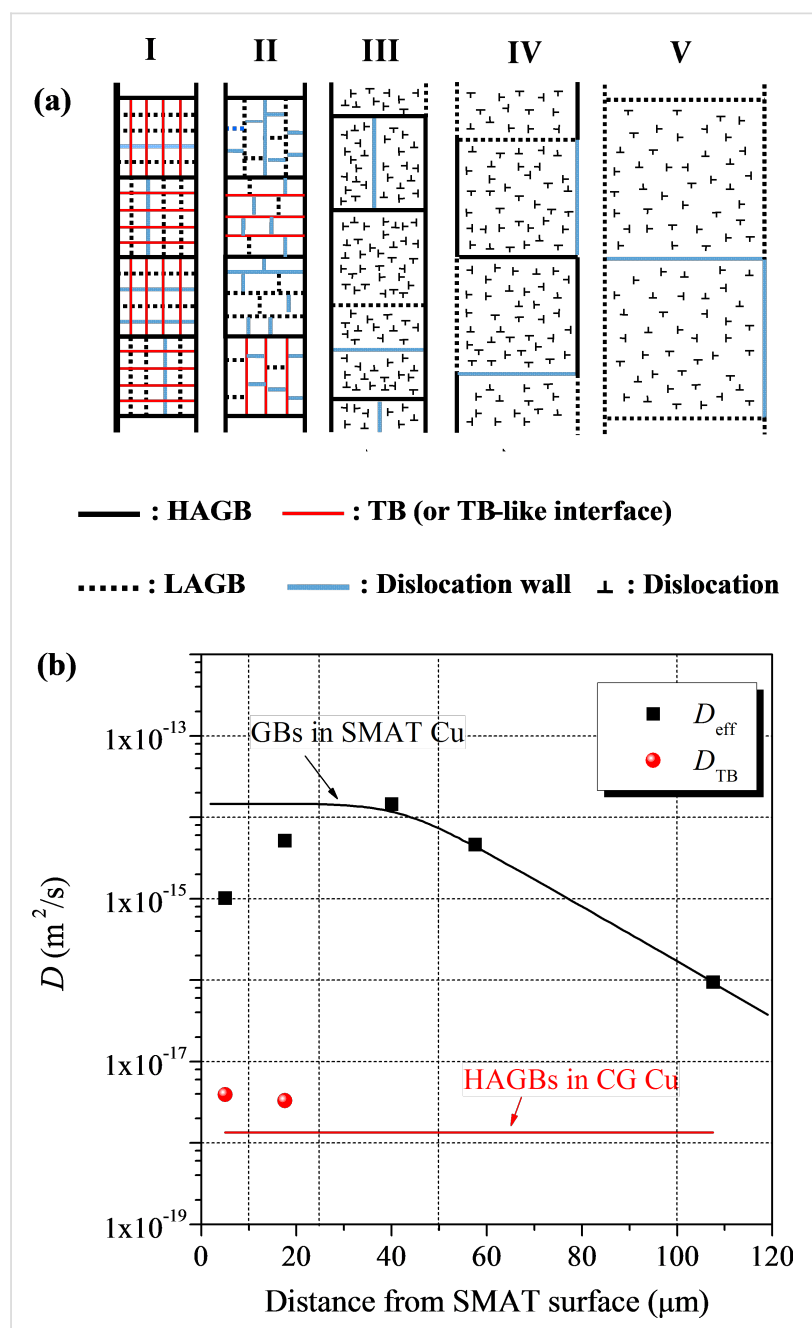

Figure 3: (a) A schematic illustration of the gradient microstructure of grain size and interface in the GNS surface layer of a SMAT Cu sample, and (b) variation in the effective diffusivity of ${ }^{63} \mathrm{Ni}$ in different regions at $130{ }^{\circ} \mathrm{C}$. Figure adapted with permission from [38], copyright 2010 Elsevier.

Since the lattice diffusion distance is negligible at the concerned temperatures, diffusion in the GNS $\mathrm{Cu}$ proceeds in accordance to Harrison's $C$-type diffusion regime [8]. Therefore, the effective diffusivities are directly related to diffusion kinetics along interfaces. As shown in Figure 3b, diffusivities along different interfaces in the GNS surface layer are compared with the diffusivity along HAGBs in a high-purity $\mathrm{CG} \mathrm{Cu}$ at $130{ }^{\circ} \mathrm{C}$. It is noted that the diffusivities along HAGBs and TBs in the first $25 \mu \mathrm{m}$ in thickness (i.e., regions I and II) were derived by using the so-called $C-B$ diffusion mode developed by Divinski et al. [17] in hierarchic microstructures. In this case, the leakage of $\mathrm{Ni}$ tracer atoms from HAGBs into TBs (i.e., $B$-regime in the mode) 
reduces the effective diffusivities in both regions. The diffusivities of HAGBs and TBs in the GNS Cu are about $1.41 \times 10^{-14}$ and $3.65 \times 10^{-18} \mathrm{~m}^{2} \cdot \mathrm{s}^{-1}$, respectively.

Table 2 summarizes several works on diffusion along TBs in pure $\mathrm{Cu}$. No comparison with diffusivity along coherent TBs can be made because no diffusion data was provided to the authors' knowledge. It is shown that the diffusivity along TBs in the SMAT $\mathrm{Cu}$ is even slightly higher than the extrapolated diffusivity along GBs in the relaxed CG sample, while those in the DPD and bicrystal samples $[42,53]$ are much lower than the latter. This suggests a much higher diffusivity along TBs in the GNS sample than in other samples. Similar with the situations of GBs (referring to the section "Diffusion behavior in nanostructured surface layers"), the significantly enhanced diffusivity along TBs in the GNS $\mathrm{Cu}$ is also expected be induced by a higher stored energy and/or with a higher density of defects. The free energy of GBs varies with the misorientation angle and forms a sharp cusp only several degrees in deviation around the corresponding angle of the coherent TBs, i.e., $70.5^{\circ}$ of twin/ matrix with [110] symmetric tilt boundary in $\mathrm{Cu}$ [54]. In the GNS layer, various dislocations are accumulated at TBs, resulting in a significant increment of interface free energy with only a slight deviation from the ideal TB misorientations [42,54].

According to a semi-empirical approach developed by Borisov et al. [55], the interface excess free energy difference $\left(\Delta \gamma_{B}\right)$, i.e., the difference between the excess free energy of interfaces in the GNS $\mathrm{Cu}$ and that of conventional GBs in a relaxed CG sample at a temperature $(T)$, may be estimated from

$$
\Delta \gamma_{\mathrm{B}}=\frac{R T}{2 a^{2} N_{\mathrm{A}}} \ln \left(\frac{D_{\mathrm{B}}}{D_{\mathrm{RGB}}}\right),
$$

where $a$ is the mean distance between atoms at the interface. $N_{\mathrm{A}}$ and $R$ are the Avogadro's number and gas constant, respectively. $D_{\mathrm{B}}$ and $D_{\mathrm{RGB}}$ are the diffusivities of Ni along interfaces in the GNS $\mathrm{Cu}$ and along conventional GBs, respectively. By using the diffusion data for different interfaces in the GNS Cu, and $D_{\mathrm{RGB}}$ from [56], $\Delta \gamma_{\mathrm{B}}$ values of different interfaces are derived. In comparison with $\gamma_{\mathrm{RGB}}\left(\approx 0.63 \mathrm{~J} \cdot \mathrm{m}^{-2}\right.$ [57]), SMAT results in an increment up to $30 \%$ in the GB excess free energy in region III, and it decreases with an increasing depth (in regions IV and V). The TB excess free energy in the first $25 \mu \mathrm{m}$ is comparable with $\gamma_{\mathrm{RGB}}$.

\section{Reactive diffusion behavior}

Reactive diffusion is of great technological importance in the metallurgical industry and in electronic materials. While a reaction process at the interface between two (or more) primary phases usually involves the nucleation and the coarsening stages of the formed phase(s), the nucleation conditions at the interface play decisive roles on the subsequent reactive diffusion process [58].

In comparison with the reactive diffusion processes in CG samples, some previous studies demonstrated different characteristics in nanostructured materials. For instance, Charlot et al. [59] showed that the mechanical milling process applied before the self-propagating high-temperature syntheses (SHS) process markedly decreased the ignition temperature $\left(\approx 100{ }^{\circ} \mathrm{C}\right)$ of the reaction in $\mathrm{Fe}$ and $\mathrm{Al}$ powder mixtures, and a nanostructured $\mathrm{Fe}-\mathrm{Al}$ intermetallic compound was synthesized after the reaction. Meanwhile, more phases from a $\mathrm{Ti}-\mathrm{Al}$ system were observed on a nanocrystalline Ti substrate with Al layer with respect to a microcrystalline substrate by Wiecinski et al. [60]. The intermetallic layer synthesized on the nanocrystalline $\mathrm{Ti}$ substrate was thicker and more homogeneous at $600{ }^{\circ} \mathrm{C}$. Nevertheless, it was noted that grain size effects on reactive diffusion characteristics were still difficult to be understood in these works, mostly because the results were obtained in binary systems with a high heat release by intermetallic formation. SHS occurred at a high temperature and significantly elevated sample temperature after the reaction ignition in such systems $[61,62]$.

In comparison, the enthalpy change and reaction temperature between Fe and $\mathrm{Zn}$ (or N) are relatively low, thus SHS will not occur and the nanostructures remain relatively stable during

\begin{tabular}{|c|c|c|c|c|c|}
\hline Base material & Diffusant & Temperature $\left({ }^{\circ} \mathrm{C}\right)$ & $D_{\mathrm{TB}}, P_{\mathrm{TB}}{ }^{\mathrm{a}}\left(\mathrm{m}^{2} \cdot \mathrm{s}^{-1}, \mathrm{~m}^{3} \cdot \mathrm{s}^{-1}\right)$ & $D_{\mathrm{RGB}}, P_{\mathrm{RGB}}{ }^{\mathrm{a}}\left(\mathrm{m}^{2} \cdot \mathrm{s}^{-1}, \mathrm{~m}^{3} \cdot \mathrm{s}^{-1}\right)$ & Ref. \\
\hline SMAT Cu & $\mathrm{Ni}$ & 130 & $3.65 \times 10^{-18}$ & $1.34 \times 10^{-18}$ & [38] \\
\hline DPD Cu & $\mathrm{Zn}$ & $\begin{array}{l}85 \\
130\end{array}$ & $\begin{array}{l}6.21 \times 10^{-20} \\
8.61 \times 10^{-19}\end{array}$ & $\begin{array}{l}5.82 \times 10^{-19} \\
2.19 \times 10^{-17}\end{array}$ & {$[42]$} \\
\hline$\Sigma 3\langle 011\rangle$ bicrystal $\mathrm{Cu}$ & $\mathrm{Au}$ & $\begin{array}{l}400 \\
500\end{array}$ & $\begin{array}{l}(0.7-11) \times 10^{-23} \\
(0.4-5.8) \times 10^{-21}\end{array}$ & $\begin{array}{l}1.18 \times 10^{-20} \\
9.6 \times 10^{-19}\end{array}$ & [53] \\
\hline
\end{tabular}

aDiffusivities were determined in the $C$-type regime in the SMAT and DPD samples. While the values were determined in the $B$-type regime in the bicrystal sample, a triple product $P$ was given. 
reactive diffusion. In this section, the reactive diffusion behavior of $\mathrm{Zn}$ and $\mathrm{N}$ into the GNS Fe prepared by SMAT $[61,62]$ will be reviewed from both kinetic and thermodynamic aspects.

\section{Promoted growth kinetics}

The growth kinetics of the $\mathrm{Fe}-\mathrm{Zn}$ compound layer (mostly $\xi-\mathrm{FeZn}_{13}$ phase) was studied in the GNS Fe sample electroplated with a $\mathrm{Zn}$ layer at different temperatures from 280 to $340{ }^{\circ} \mathrm{C}$ [61]. It was found that the $\mathrm{Fe}-\mathrm{Zn}$ compound layer formed on the GNS sample is much thicker than that on the CG sample under the same isothermal annealing treatment. According to the relationship between the measured thickness $(l)$ of compound layers, diffusion temperature $(T)$ and duration $(t)$, the growth kinetics was determined from

$$
\ln k^{2}=\ln \left(k_{0}^{2}\right)-\frac{Q}{R T}
$$

where $k$ is the growth constant derived from

$$
l=k \sqrt{t}
$$

The pre-exponential factor $k_{0}$ is a constant related to atomic diffusion, and $Q$ is the activation enthalpy for the growth of compound layer. As derived from Figure $4 \mathrm{a}$, the activation enthalpy for the growth of the compound layer in the GNS sample is $108.0 \pm 20.7 \mathrm{~kJ} \cdot \mathrm{mol}^{-1}$, which is much lower than that in the CG sample $\left(167.1 \pm 10.1 \mathrm{~kJ} \cdot \mathrm{mol}^{-1}\right)$.

Significantly promoted growth kinetics has also been observed in the GNS Fe during gas nitriding at lower temperatures
$[62,63]$. A continuous nitride surface layer (mostly $\varepsilon-\mathrm{Fe}_{2-3} \mathrm{~N}$ and $\gamma^{\prime}-\mathrm{Fe}_{4} \mathrm{~N}$ ) of $\approx 10 \mu \mathrm{m}$ in thickness was formed on the GNS sample after nitriding at $300{ }^{\circ} \mathrm{C}$ for $9 \mathrm{~h}$. In comparison, there was no such nitride layer formed on the original CG sample after the same nitriding treatment.

The growth kinetics of the formed compound layer should be controlled by diffusion processes in both the substrates and the compound layer [61]. While the grain size of $\mathrm{Fe}$ in the nanostructured surface layer is much smaller than that in the CG matrix, grain sizes of the formed compounds in the GNS sample are still much smaller than those formed in the CG sample $[61,62]$. Therefore, diffusion of alloying elements in the GNS sample and in the compounds layer is evidently accelerated, and a smaller activation enthalpy is obtained than in the CG sample.

The promoted growth kinetics in GNS samples may also be understood in terms of the reaction kinetics of nucleation and growth. Because GBs usually act as preferable nucleation sites, the existence of a large number of GBs in the nanostructured substrate may result in a significant improvement in the reaction between alloying elements and substrate atoms. The nucleation rate, $\dot{G}(T)$, can be written as [64]:

$$
\dot{G}(T)=\omega C_{0} \exp \left(-\frac{Q}{R T}\right) \exp \left(-\frac{\Delta G^{*}}{R T}\right)
$$

where $\Delta G^{*}$ is the critical Gibbs energy for nucleation, $\omega$ is a frequency factor, and $C_{0}$ is the number of atoms at contacting interfaces. While the value of the critical Gibbs energy for nu-
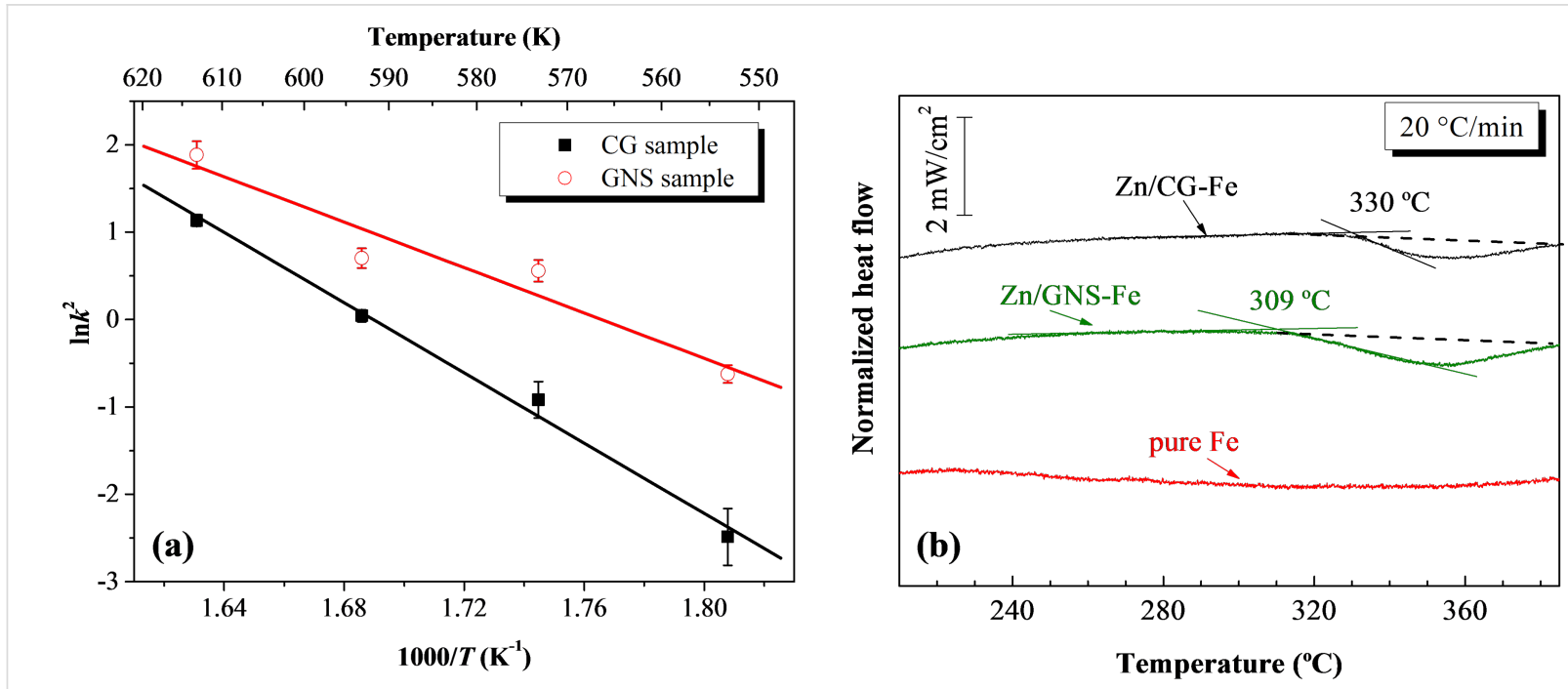

Figure 4: (a) The dependence of the growth constant $k^{2}$ on the reciprocal annealing temperature during reactive diffusion of Zn on the GNS and CG Fe samples, and (b) thermal analyses of the $\mathrm{Zn} / \mathrm{GNS}-\mathrm{Fe}$ and the $\mathrm{Zn} / \mathrm{CG}-\mathrm{Fe}$ couples at a heating rate of $20^{\circ} \mathrm{C} \cdot \mathrm{min}^{-1}$. Figure adapted with permission from [61], copyright 2012 Elsevier. 
cleation at GBs is smaller than the value at other regions along the surface, the nucleation rate increases significantly with decreasing grain size in the nanostructured surface layer. The growth kinetics of the nuclei of formed compounds is expected to be significantly promoted by abundant GBs in the GNS layer at the earlier stage of reaction, mostly due to the accelerated diffusion rates of alloying elements along them [32,61].

It is also noted that homogenous reaction layers of $\mathrm{FePt}$ and FePt with $\approx 10$ atom $\% \mathrm{Ag}$ have been synthesized in $\mathrm{Pt} / \mathrm{Fe}$ and $\mathrm{Pt} / \mathrm{Ag} / \mathrm{Fe}$ thin films, respectively, after annealing at temperatures when the bulk diffusion processes are still frozen [65] The formation processes have been interpreted as a GB-diffusion-induced solid-state reaction in which the reaction interfaces migrate perpendicularly to the original GB plane, based on corresponding depth profiles of the element concentrations in both systems. This mechanism might also contribute to the promoted growth kinetics of a compound layer in GNS samples.

\section{Stored energy and reaction thermodynamics}

Thermal analysis (see Figure $4 b$ ) of the reaction between $\mathrm{Zn}$ and GNS Fe showed that an exothermic peak appears at about $309{ }^{\circ} \mathrm{C}$, which is $\approx 21{ }^{\circ} \mathrm{C}$ lower than that in the $\mathrm{Zn} / \mathrm{CG}-\mathrm{Fe}$ couple. Mostly, the $\xi-\mathrm{FeZn}_{13}$ phase formed after the exothermic peaks in both samples. In addition, the reaction enthalpy change is $\approx 58.6 \mathrm{~mJ} \cdot \mathrm{cm}^{-2}$ in the $\mathrm{Zn} / \mathrm{GNS}-\mathrm{Fe}$ couple, almost double that in the $\mathrm{Zn} / \mathrm{CG}-\mathrm{Fe}$ couple [61].

In addition to the promoted nucleation and growth kinetics related with numerous GBs, as discussed in the last section, the higher stored free energy might also contribute to the lower onset temperature and higher reaction enthalpy change of $\mathrm{Fe}-\mathrm{Zn}$ reaction in the GNS sample. As we know, stored energy values in metallic systems processed by conventional cold working are typically within $0.01-0.2 \mathrm{~kJ} \cdot \mathrm{mol}^{-1}$, and they may change either the kinetics or the path of a phase transition in solid-state with a typical free energy change of $0.5-3 \mathrm{~kJ} \cdot \mathrm{mol}^{-1}$ [66]. While the stored energy may be much higher because GBs are associated with a higher stored free energy in the GNS substrates produced by SMAT [38], an additional driving force will be provided for the formation of intermetallic compounds. For example, the stored energy value in the GNS Fe is estimated to be $\approx 2.07 \mathrm{~kJ} \cdot \mathrm{mol}^{-1}$ according to the value in a nanostructured $\mathrm{Fe}$ synthesized by ball milling $[61,67]$. In comparison, the standard Gibbs free energy change for the formation of $\mathrm{FeZn}_{13}$ from elemental $\mathrm{Fe}$ and $\mathrm{Zn}$ atoms is about $-2.50 \mathrm{~kJ} \cdot \mathrm{mol}^{-1}$ at $330{ }^{\circ} \mathrm{C}$ [68]. With the stored excess energy in the GNS layer, the Gibbs free energy change for this reaction becomes $-4.57 \mathrm{~kJ} \cdot \mathrm{mol}^{-1}$, so that the nucleation rate will be raised and the onset temperature may be decreased for the $\mathrm{Fe}-\mathrm{Zn}$ reaction in the $\mathrm{Zn} / \mathrm{GNS}-\mathrm{Fe}$ couple [61].
The stored energy in the nanostructured surface layer also contributed to the promoted formation process of nitrides during nitriding GNS Fe at low temperatures [62]. The Gibbs free energy change for nitrides formation in the $\mathrm{CG} \mathrm{Fe}$ at $500{ }^{\circ} \mathrm{C}$ is about $-8.22 \mathrm{~kJ} \cdot \mathrm{mol}^{-1}$ for the $\gamma^{\prime}$ phase and $-1.69 \mathrm{~kJ} \cdot \mathrm{mol}^{-1}$ for the $\varepsilon$ phase. Both values might become positive and nitrides could not form at $300{ }^{\circ} \mathrm{C}$. However, the free energy changes for the nitrides formation became negative with the stored excess energy in the nanostructured $\mathrm{Fe}$ phase, so that their formation became possible at the same temperature. The contributions of stored excess energy to the promoted nitriding kinetics have been confirmed by measurements on critical nitrogen potentials for the formation of $\varepsilon$ phase. As shown in Figure 5, the $\varepsilon-\mathrm{Fe}_{2-3} \mathrm{~N}$ phase formed at a lower temperature or with a smaller nitrogen potential in the GNS Fe sample in comparison with those in the CG sample $[63,69]$.

\section{Surface alloying of GNS materials}

Inspired by the significantly promoted diffusion and chemical reaction kinetics in GNS layers, many works have been carried out on advancing surface alloying techniques of metals with a preformed nanostructured surface layer. The advantages are distinct, for example, improving surface properties such as wear and corrosion resistance with higher energy/time efficiency, reducing work-piece distortion and/or grain coarsening. In addition, GNS surface layers with promoted diffusion and chemical reaction were also produced to enhance formation of surface layers with modified microstructure and phase constitutions, in order to be made more protective and functional.

\section{Surface alloying processes}

Lower-temperature processes: Surface alloying processes, such as nitriding and aluminizing, have been achieved on various engineering metals with a GNS surface layer at temperatures much lower than the conventional processing temperatures, and properties such as resistance to wear and corrosion were significantly improved.

Gas nitriding of steel is conventionally carried out at temperatures above $500{ }^{\circ} \mathrm{C}$ over a long duration $(60-80 \mathrm{~h})$. A representative nitriding steel $38 \mathrm{CrMoAl}$ was submitted to SMAT followed by gas nitriding at $400{ }^{\circ} \mathrm{C}$ for $30 \mathrm{~h} \mathrm{[70]}$. As shown in Figure 6, a continuous compound layer containing mostly nanosized $\varepsilon-\mathrm{Fe}_{2-3} \mathrm{~N}$ and $\gamma^{\prime}-\mathrm{Fe}_{4} \mathrm{~N}$ phases followed by a diffusion zone was formed on the GNS sample, and the total thickness of the compound layer and the diffusion layer is more than $200 \mu \mathrm{m}$. In comparison, no continuous compound layer was formed on the CG sample after the same nitriding process, and only a diffusion zone with the thickness of $\approx 50 \mu \mathrm{m}$ was observed. Thus, a much higher wear resistance was obtained due to the thicker nitride layer with increased hardness on the GNS sample. 

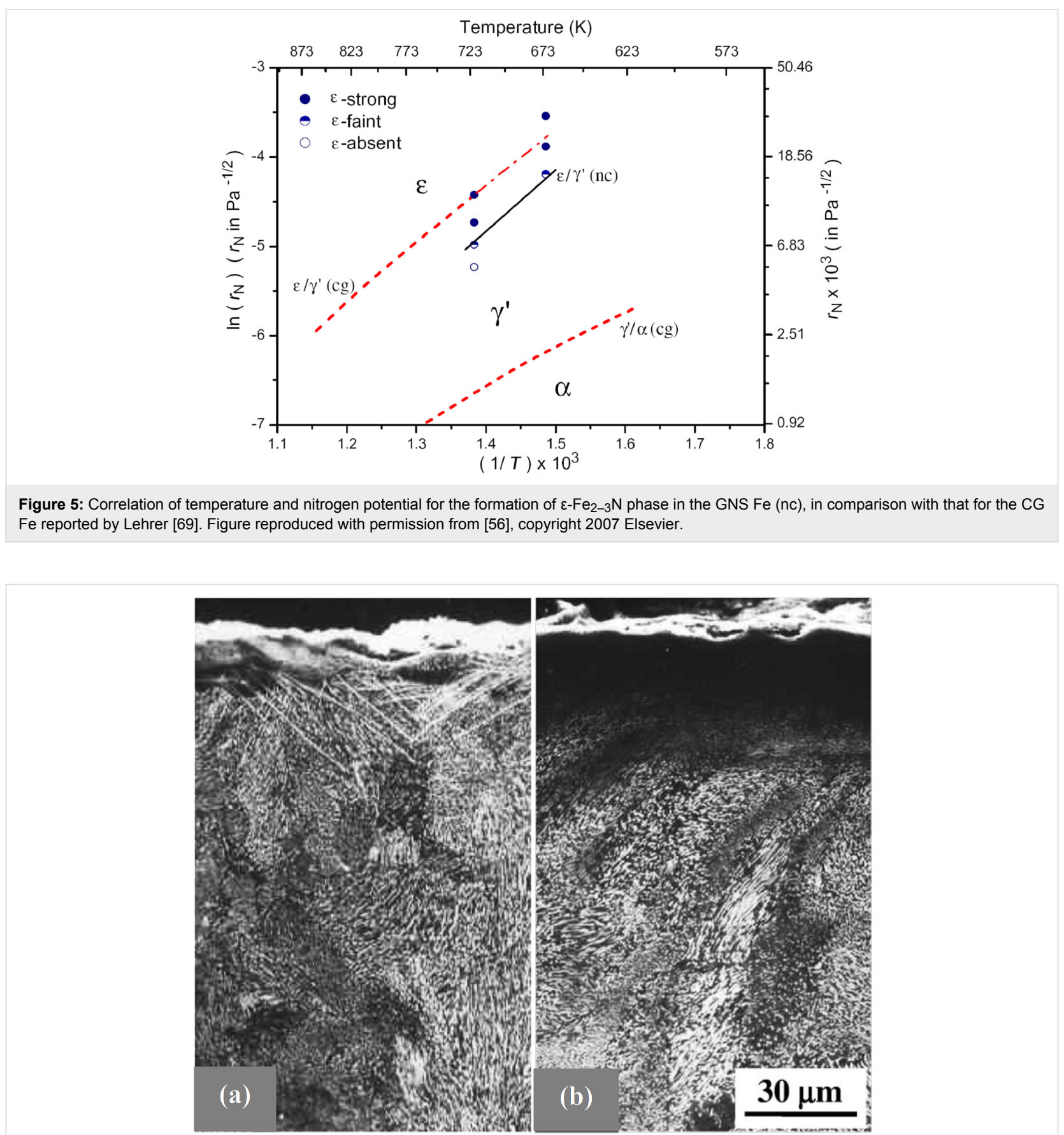

Figure 6: Cross-sectional observations of (a) the CG and (b) the GNS $38 \mathrm{CrMoAl}$ samples after gas nitriding at $400{ }^{\circ} \mathrm{C}$ for $30 \mathrm{~h}$. Figure reproduced with permission from [70], copyright 2008 Elsevier.

Similarly, preformed GNS surface layers have also been used to successfully lower the boronizing temperature of tool steel [7175], aluminizing temperature of $\mathrm{Mg}$ alloys [76] and ferritic steel $[77,78]$, and nitriding temperature of plain carbon steel [79], stainless steel [80-82], Ti and Ti alloys [83-85], etc.

In addition, the simultaneous surface mechanical and alloying treatment has also been developed to promote the formation of alloyed or compound layers. By loading specimens, packaluminizing powder and alloy balls in a chamber, and then mechanically vibrating the chamber at an elevated temperature $\left(\approx 600{ }^{\circ} \mathrm{C}\right.$ ), an aluminized coating consisting mostly of $\mathrm{Fe}_{2} \mathrm{Al}_{5}$ phase with some $\mathrm{FeAl}_{3}$ and $\mathrm{FeAl}$ phases has been produced on low-carbon steel [86] and Fe-13Cr steel [87] by Zhan et al. While grain growth is effectively hindered in the simultaneous treatment, the alloyed/compound coating should be thicker than 
that formed by SMAT with subsequent alloying treatment. Furthermore, the diffusive transport of species and phase transitions might be significantly promoted during SPD, which usually triggers the states equivalent to higher temperatures [88]. For example, Straumal et al. [89] demonstrated that high pressure torsion at room temperature produced a solid solution with a certain steady-state concentration equal to the solubility limit at an effective temperature of $680{ }^{\circ} \mathrm{C}$ in $\mathrm{Cu}-\mathrm{Ag}$ alloys with different initial states. This will also contribute to the promoted surface alloying kinetics during simultaneous treatment, and might even result in the formation of metastable phases. However, deficiencies of such a treatment mainly come from technical difficulties in achieving simultaneous mechanical and alloying processes at elevated temperatures.

Duplex surface alloying processes: For surface alloying processes such as chromizing and aluminizing, temperatures as high as $\approx 1000{ }^{\circ} \mathrm{C}$ are conventionally required to achieved a satisfying (in terms of thickness and phase constitutions) alloyed/compound surface layer on steels. The formation kinetics of an alloyed layer might be significantly promoted by introducing a GNS surface layer. However, the formed alloyed layer was typically only on the micrometer scale in thickness at lower temperatures, even though a higher ratio was achieved by comparing the thickness of the alloyed layer on the GNS sample with that on the CG counterpart sample. A further increased processing temperature decreased the ratio or even reduce the thickness value due to the instability of nanostructures at higher temperatures, as mentioned previously. In addition, phase constitutions in compound layers formed at lower temperatures were sometimes different (sometimes not as satisfying) from conventional ones formed at higher temperatures. A duplex surface alloying processes, that is, a lower temperature $\left(T_{1}\right)$ process followed by a higher temperature $\left(T_{2}\right)$ process, have been developed to overcome these limitations $[32,33,90]$. The process at $T_{1}$ allowed an effective diffusion of alloying elements and compound formation along GBs, while the nanostructures were relatively stable. The following process at $T_{2}$ enhanced the growth (or phase transformation) kinetics of alloyed layers because the thermal stability in the surface layers was improved by the introduced alloying elements and/or compounds during the previous process.

The effects of both processes at $T_{1}$ and at $T_{2}$ on the formation of a chromized layer have been studied on a GNS H13 steel sample prepared by SMAT [33]. As shown in Figure 7, the thickness of the compound layer $\left((\mathrm{Cr}, \mathrm{Fe}){ }_{2} \mathrm{~N}_{1-\mathrm{x}}\right.$ and $(\mathrm{Cr}, \mathrm{Fe}){ }_{23} \mathrm{C}_{6}$ phases) increased gradually with increasing $T_{1}$ before reaching a maximum at $\approx 600{ }^{\circ} \mathrm{C}$ and then decreased with a further increase in $T_{1}$, when $T_{2}$ was fixed at $950{ }^{\circ} \mathrm{C}$ for $120 \mathrm{~min}$. In comparison, the compound layer formed on the $\mathrm{CG}$ sample remained approximately a constant thickness with increasing $T_{1}$. When $T_{1}$ was fixed at $600{ }^{\circ} \mathrm{C}$ for $120 \mathrm{~min}$, a much thicker compound surface layer was formed on the GNS sample than on the CG sample after the chromizing process at $T_{2}$ from 950 to $1050{ }^{\circ} \mathrm{C}$. Subsequently, a duplex chromizing process at $600{ }^{\circ} \mathrm{C}$ followed by another at $1050{ }^{\circ} \mathrm{C}$ was employed to chromize the GNS sample. A chromized surface layer of $\approx 30 \mu \mathrm{m}$ in thickness was formed, much thicker than that on the CG sample $(\approx 10 \mu \mathrm{m})$ after the same chromizing process. And
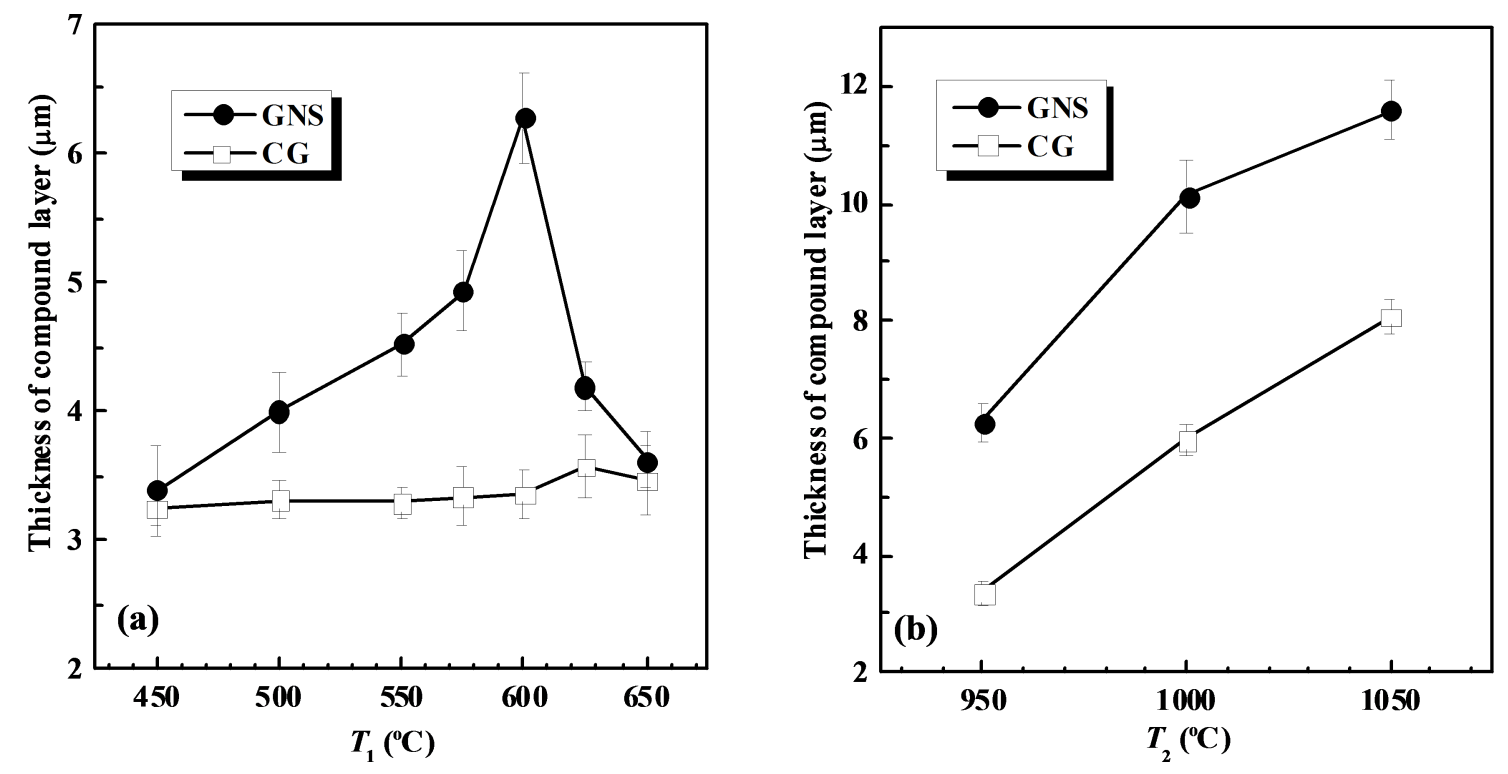

Figure 7: Effects of (a) $T_{1}$ (with $T_{2}=950{ }^{\circ} \mathrm{C}$ for $120 \mathrm{~min}$ ) and (b) $T_{2}$ (with $T_{1}=600{ }^{\circ} \mathrm{C}$ for $120 \mathrm{~min}$ ) on the compound layer thickness in the GNS and the CG H13 steel samples after duplex chromizing processes. Figure reproduced with permission from [33], copyright 2010 Elsevier. 
the wear resistance of the GNS sample after the duplex chromizing was significantly enhanced due to the higher surface hardness, as well as the graded distribution of composition, structure, and hardness.

In addition, a duplex aluminizing process including a packed aluminization process at $560{ }^{\circ} \mathrm{C}$ and a subsequent diffusion annealing treatment at $720{ }^{\circ} \mathrm{C}$ was developed for the P92 ferritic-martensitic (F-M) steel with a preformed GNS surface layer [90]. A lower aluminum content aluminide (AlFe and $\alpha$-(FeAl)) surface layer of $\approx 17 \mu \mathrm{m}$ in thickness was produced on the F-M steel. Experiments showed that the oxidation resistance of the F-M steel in steam was significantly promoted at higher temperatures. In comparison with the brittle Al-rich aluminide (mostly $\mathrm{Al}_{5} \mathrm{Fe}_{2}$ ) surface layer formed on the CG sample after the same duplex process, the lower content $\mathrm{Al}$ aluminide layer formed on the GNS sample is more resistant to cracking and has better adhesion to the substrate [91].

\section{Other diffusion-related processes}

The coating/substrate interface is usually the most vulnerable part in a coated component due to the lower bonding strength between them. Some experiments showed that the bonding property of a coating on a substrate might be improved by preforming a GNS surface layer on the substrate. This was mostly due to the promoted atomic diffusion kinetics in the GNS layer, which strengthened the metallurgical bonding across the interface. For example, the interdiffusion distance between the elements of a cold-sprayed $\mathrm{Zn}-\mathrm{Al}$ coating and a GNS interstitial-free steel substrate was significantly increased in the as-sprayed state, resulting in an increment of $\approx 30 \%$ in the bonding strength of the coating on the substrate [92]. In addition, a higher film cohesion strength and better wear resistance have been achieved on the 304 stainless steel with a preformed GNS surface layer after being sputter-deposited a DLC coating, in comparison with that of the DLC-coated CG sample [93].

A GNS surface layer has also been employed to facilitate the formation of nanoporous titania on the commercial pure $\mathrm{Ti}$ $[94,95]$, which is used as an important material in human body implantation. After immersion in the $\mathrm{H}_{2} \mathrm{O}_{2}$ solution for $24 \mathrm{~h}$ at room temperature, crystallized titania with the nanoporous structure was synthesized on the GNS Ti plate, while only interfacial corrosion was observed on the CG sample. By studying the structure and surface morphology evolution of the GNS sample in the $\mathrm{H}_{2} \mathrm{O}_{2}$ solution, Wen et al. [95] revealed that the accelerated formation of nanoporous structure was mostly due to the higher chemical reactivity of the GNS Ti, which promoted the decomposition of $\mathrm{H}_{2} \mathrm{O}_{2}$ and the formation of amorphous titania. Furthermore, the formed titania showed an increased crystallinity and retained the nanoporous structure even after calcination at $600{ }^{\circ} \mathrm{C}$ [94]. These works indicated the possibility to improve the bioactivity of titanium bone implants and to accelerate osseointegration by introducing a preformed GNS surface layer [95].

Different from the phenomena that thicker alloyed layers commonly form on GNS materials, a much thinner oxide layer was observed on a GNS 9Cr2WVTa F-M steel, i.e., the oxidation resistance of the steel was improved by the preformed GNS surface layer [96]. As shown in Figure 8, a compact oxide layer with the thickness of $\approx 0.5 \mu \mathrm{m}$ was formed on the GNS sample after oxidation at $600{ }^{\circ} \mathrm{C}$ for $510 \mathrm{~h}$ in air. In comparison, it was within $8-50 \mu \mathrm{m}$ in thickness and with various cracks on the oxidized CG sample. Further comparisons of composition and phase distributions indicated that the oxide scale was enriched
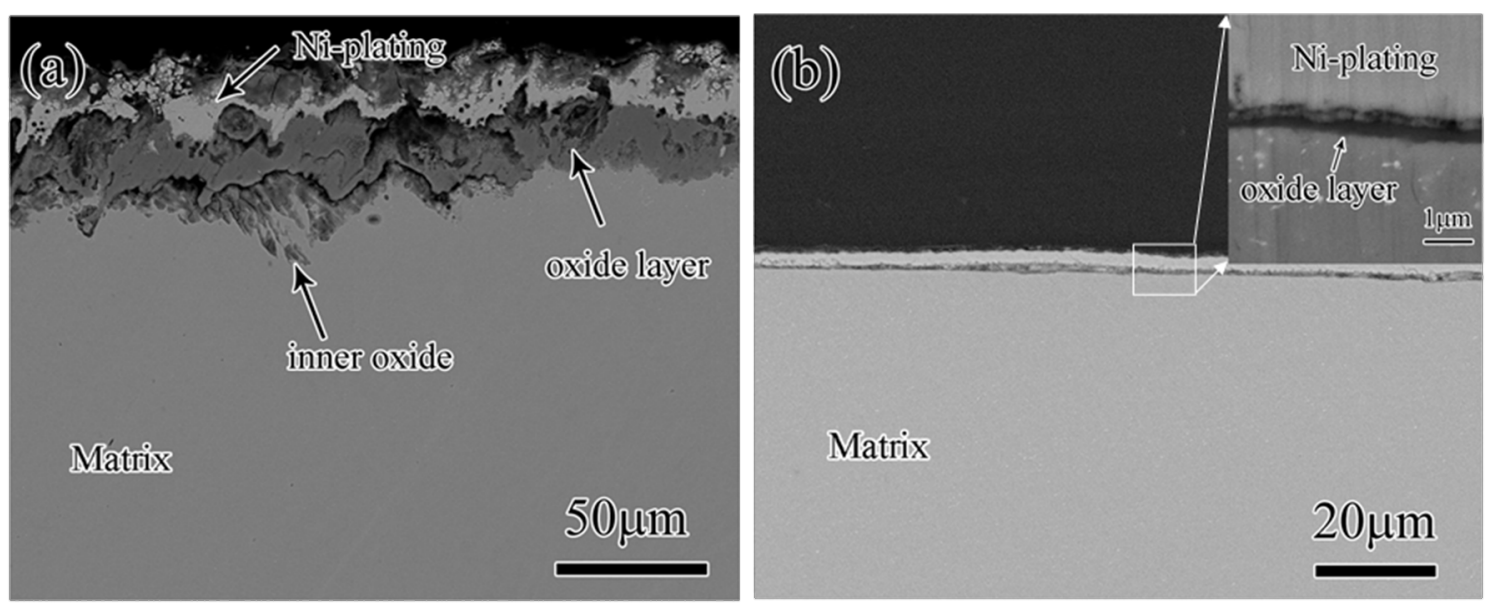

Figure 8: Typical cross-sectional morphologies of (a) the CG and (b) the GNS $9 \mathrm{Cr} 2 \mathrm{WVTa}$ F-M steel samples oxidized at $600{ }^{\circ} \mathrm{C}$ for $510 \mathrm{~h}$ in air. Insert in (b) shows a magnified image of the boxed region. Figure reproduced with permission from [96], copyright 2016 Elsevier. 
with $\mathrm{Mn}$ and contained a large amount of $\mathrm{Mn}_{2} \mathrm{O}_{3}$ phase on the GNS sample, while no Mn enrichment was observed and the oxide scale was mainly composed of $\left(\mathrm{Fe}_{0.6} \mathrm{Cr}_{0.4}\right)_{2} \mathrm{O}_{3}$ phase on the CG sample. Analysis confirmed that the markedly improved oxidation resistance of the GNS sample mostly resulted from the quicker formation of the Mn-enriched oxide scale. While the $\mathrm{Mn}$ oxide (i.e., $\mathrm{Mn}_{2} \mathrm{O}_{3}$ ) possessed the most negative free-energy among all possible oxides from 9Cr2WVTa steel, its formation was accelerated by the higher diffusivities in the GNS surface layer. In addition, the higher binding energy between $\mathrm{Mn}$ and vacancies, of which the concentration was much larger in the GNS sample than in the CG sample, also contributed to the quicker formation of Mn-enriched oxide scale $[45,96,97]$.

\section{Conclusion}

Due to the importance of understanding the diffusion and surface alloying behavior of GNS metals, interfacial diffusion and reactive diffusion have been systematically studied on this kind of material and summarized in this review. It was confirmed that interfacial diffusivities in GNS layers are typically 3-5 orders of magnitude higher than those along GBs in CG counterparts. This was mainly associated with a higher energy state of GBs induced by the plastic deformation with high strain and strain rates. Meanwhile, the chemical diffusion and reaction kinetics have been promoted in GNS surface layers, in which numerous GBs accelerate atomic diffusion and increase the nucleation and growth rates of formed compounds. The extra stored free energy at GBs also thermodynamically facilitate the formation of compounds in GNS surface layers.

Benefitting from the promoted diffusion and reaction kinetics, different surface alloying treatments have been achieved at much lower temperatures on materials with a preformed GNS surface layer than those of the conventional treatments on $\mathrm{CG}$ samples, such as nitriding, boronizing, and aluminizing. In addition, some other diffusion-related properties, such as bonding strength of coating on substrate, bioactivity of Ti and Ti alloys, and oxidation resistance of F-M steels, have also been enhanced by GNS surface layers. By applying a duplex approach including a lower temperature step and a subsequent higher temperature step, chromizing and aluminizing treatments were further modified to obtain an alloyed (or compound) surface layer with larger thickness and better properties.

Studies of diffusion behavior might shed light on the structural characteristics and properties of internal interfaces in nanostructured materials. Novel microstructures such as LAGB-dominant interfaces and nanolaminates have been synthesized in GNS metals recently $[98,99]$. They showed unique performance, for example, ultrahigh hardness accompanied by superi- or thermal stability. Studying the diffusion kinetics and relative behavior in GNS layers with such novel microstructures is expected to help understand their unique features and provide insights on tailoring the microstructure for better performance.

Combined with surface alloying, a graded transition in composition and/or phase constitution is formed in a GNS surface layer. Besides the enhanced properties, novel and unique properties of such a material with graded distribution of microstructure, composition, and phase are expected to be further explored. For example, a synergic improvement in strength, ductility, and resistance to wear and corrosion might be expected, while the distribution of microstructure, composition, and phase can be controlled within broader ranges due to the promoted diffusion kinetics in the preformed GNS layers.

\section{Acknowledgements}

Financial support from the Ministry of Science and Technology projects of China (No. 2012CB932201), the National Natural Science Foundation of China (Nos. 51231006, 91226204), and Shenyang National Laboratory for Materials Science are acknowledged.

\section{References}

1. Fang, T. H.; Li, W. L.; Tao, N. R.; Lu, K. Science 2011, 331, 1587-1590. doi:10.1126/science.1200177

2. Wu, X.; Jiang, P.; Chen, L.; Yuan, F.; Zhu, Y. T. Proc. Natl. Acad. Sci. U. S. A. 2014, 111, 7197-7201. doi:10.1073/pnas.1324069111

3. Wei, Y.; Li, Y.; Zhu, L.; Liu, Y.; Lei, X.; Wang, G.; Wu, Y.; Mi, Z.; Liu, J.; Wang, H.; Gao, H. Nat. Commun. 2014, 5, 3580. doi:10.1038/ncomms4580

4. Han, Z.; Zhang, Y.; Lu, K. J. Mater. Sci. Technol. 2008, 24, 483-494.

5. Wang, Z. B.; Tao, N. R.; Li, S.; Wang, W.; Liu, G.; Lu, J.; Lu, K. Mater. Sci. Eng., A 2003, 352, 144-149. doi:10.1016/S0921-5093(02)00870-5

6. Yang, L.; Tao, N. R.; Lu, K.; Lu, L. Scr. Mater. 2013, 68, 801-804. doi:10.1016/j.scriptamat.2013.01.031

7. Huang, H. W.; Wang, Z. B.; Lu, J.; Lu, K. Acta Mater. 2015, 87, 150-160. doi:10.1016/j.actamat.2014.12.057

8. Harrison, L. G. Trans. Faraday Soc. 1961, 57, 1191-1199. doi:10.1039/tf9615701191

9. Lu, K.; Lu, J. J. Mater. Sci. Technol. 1999, 15, 193-197.

10. Lu, K.; Lu, J. Mater. Sci. Eng., A 2004, 375-377, 38-45. doi:10.1016/j.msea.2003.10.261

11. Lu, K. Nat. Rev. Mater. 2016, 1, 16019. doi:10.1038/natrevmats.2016.19

12. Gleiter, H. Materials with Ultrafine Grain Size. In Proceedings of the 2nd Riso International Symposium on Metallurgy and Materials Science, Roskilde, Denmark; Hansen, N., Ed.; 1981; pp 15-21.

13. Gleiter, H. Prog. Mater. Sci. 1989, 33, 223-315. doi:10.1016/0079-6425(89)90001-7

14. Horváth, J.; Birringer, R.; Gleiter, H. Solid State Commun. 1987, 62, 319-322. doi:10.1016/0038-1098(87)90989-6 
15. Schumacher, S.; Birringer, R.; Strauss, R.; Gleiter, H. Acta Metall. 1989, 37, 2485-2488. doi:10.1016/0001-6160(89)90046-1

16. Höfler, H. J.; Averback, R. S.; Hahn, H.; Gleiter, H. J. Appl. Phys. 1993, 74, 3832-3839. doi:10.1063/1.354477

17. Divinski, S. V.; Hisker, F.; Kang, Y.-S.; Lee, J.-S.; Herzig, C. Acta Mater. 2004, 52, 631-645. doi:10.1016/j.actamat.2003.09.045

18. Würschum, R.; Farber, P.; Dittmar, R.; Scharwaechter, P.; Frank, W.; Schaefer, H.-E. Phys. Rev. Lett. 1997, 79, 4918-4921. doi:10.1103/PhysRevLett.79.4918

19. Würschum, R.; Reimann, K.; Gruss, S.; Kubler, A.; Scharwaechter, P.; Frank, W.; Kruse, O.; Carstanjen, H. D.; Schaefer, H. E. Philos. Mag. B 1997, 76, 407-417. doi:10.1080/01418639708241104

20. Kolobov, Yu. R.; Grabovetskaya, G. P.; Ivanov, M. B.; Zhilyaev, A. P.; Valiev, R. Z. Scr. Mater. 2001, 44, 873-878. doi:10.1016/S1359-6462(00)00699-0

21. Amouyal, Y.; Divinski, S. V.; Estrin, Y.; Rabkin, E. Acta Mater. 2007, 55, 5968-5979. doi:10.1016/j.actamat.2007.07.026

22. Nazarov, A. A.; Romanov, A. E.; Valiev, R. Z. Scr. Mater. 1996, 34 , 729-734. doi:10.1016/1359-6462(95)00573-0

23. Valiev, R. Z.; Islamgaliev, R. K.; Alexandrov, I. V. Prog. Mater. Sci. 2000, 45, 103-189. doi:10.1016/S0079-6425(99)00007-9

24. Wilde, G.; Ribbe, J.; Reglitz, G.; Wegner, M.; Rösner, H.; Estrin, Y.; Zehetbauer, M.; Setman, D.; Divinski, S. Adv. Eng. Mater. 2010, 12, 758-764. doi:10.1002/adem.200900333

25. Straumal, B. B.; Kogtenkova, O. A.; Muktepavela, F.; Kolesnikova, K. I.; Bulatov, M. F.; Straumal, P. B.; Baretzky, B. Mater. Lett. 2015, 159 432-435. doi:10.1016/j.matlet.2015.07.038

26. Ribbe, J.; Baither, D.; Schmitz, G.; Divinski, S. V. Phys. Rev. Lett. 2009, 102, 165501.

27. Divinski, S. V.; Ribbe, J.; Baither, D.; Schmitz, G.; Reglitz, G.; Rösner, H.; Sato, K.; Estrin, Y.; Wilde, G. Acta Mater. 2009, 57, 5706-5717. doi:10.1016/j.actamat.2009.07.066

28. Klinger, L.; Rabkin, E. Acta Mater. 1999, 47, 725-734. doi:10.1016/S1359-6454(98)00420-0

29. Tao, N. R.; Wang, Z. B.; Tong, W. P.; Sui, M. L.; Lu, J.; Lu, K. Acta Mater. 2002, 50, 4603-4616. doi:10.1016/S1359-6454(02)00310-5

30. Wang, K.; Tao, N. R.; Liu, G.; Lu, J.; Lu, K. Acta Mater. 2006, 54, 5281-5291. doi:10.1016/j.actamat.2006.07.013

31. Wang, Z. B.; Tao, N. R.; Tong, W. P.; Lu, J.; Lu, K. Acta Mater. 2003, 51, 4319-4329. doi:10.1016/S1359-6454(03)00260-X

32. Wang, Z. B.; Lu, J.; Lu, K. Acta Mater. 2005, 53, 2081-2089. doi:10.1016/j.actamat.2005.01.020

33. Lu, S. D.; Wang, Z. B.; Lu, K. Mater. Sci. Eng., A 2010, 527, 995-1002. doi:10.1016/j.msea.2009.10.030

34. Srikrishnan, V.; Ficalora, P. J. Metall. Trans. A 1975, 6, 2095-2102. doi:10.1007/BF03161836

35. Kaur, I.; Gust, W.; Kozma, L. Handbook of Grain and Interphase Boundary Diffusion Data; Ziegler Press: Stuttgart, Germany, 1989; Vol. 1 and 2. doi:10.1002/crat.2170251124

36. Callister, W. D. Materials Science and Engineering: An Introduction, 5th ed.; John Wiley \& Sons: New York, NY, U.S.A., 2000.

37. Suryanarayana, C. Int. Mater. Rev. 1995, 40, 41-64. doi:10.1179/imr.1995.40.2.41

38. Wang, Z. B.; Lu, K.; Wilde, G.; Divinski, S. V. Acta Mater. 2010, 58, 2376-2386. doi:10.1016/j.actamat.2009.12.024

39. Amouyal, Y.; Divinski, S. V.; Klinger, L.; Rabkin, E. Acta Mater. 2008, 56, 5500-5513. doi:10.1016/j.actamat.2008.07.029

40. Divinski, S. V.; Reglitz, G.; Rösner, H.; Estrin, Y.; Wilde, G. Acta Mater. 2011, 59, 1974-1985. doi:10.1016/j.actamat.2010.11.063
41. Dickenscheid, W.; Birringer, R.; Gleiter, H.; Kanert, O.; Michel, B.; Günther, B. Solid State Commun. 1991, 79, 683-686. doi:10.1016/0038-1098(91)90613-Z

42. Wang, H. L.; Wang, Z. B.; Lu, K. Acta Mater. 2011, 59, 1818-1828. doi:10.1016/j.actamat.2010.11.048

43. Kaur, I.; Mishin, Y.; Gust, W. Fundamentals of Grain and Interphase Boundary Diffusion; John Wiley \& Sons: Chichester, West Sussex, United Kingdom, 1995.

44. Mishin, Y. M. Defect Diffus. Forum 2001, 194-199, 1113-1125. doi:10.4028/www.scientific.net/DDF.194-199.1113

45. Wang, Z. B.; Tao, N. R.; Tong, W. P.; Lu, J.; Lu, K. Defect Diffus. Forum 2006, 249, 147-154. doi:10.4028/www.scientific.net/DDF.249.147

46. Straumal, B. B.; Mazilkin, A. A.; Baretzky, B. Curr. Opin. Solid State Mater. Sci. 2016, 20, 247-256. doi:10.1016/j.cossms.2016.05.006

47. Straumal, B. B.; Sauvage, X.; Baretzky, B.; Mazilkin, A. A.; Valiev, R. Z. Scr. Mater. 2014, 70, 59-62. doi:10.1016/j.scriptamat.2013.09.019

48. Divinski, S.; Lohmann, M.; Herzig, C.; Straumal, B.; Baretzky, B.; Gust, W. Phys. Rev. B 2005, 71, 8. doi:10.1103/PhysRevB.71.104104

49. Straumal, B. B.; Noskovich, O. I.; Semenov, V. N.; Shvindlerman, L. S.; Gust, W.; Predel, B. Acta Metall. Mater. 1992, 40, 795-801. doi:10.1016/0956-7151(92)90021-6

50. Cantwell, P. R.; Tang, M.; Dillon, S. J.; Luo, J.; Rohrer, G. S.; Harmer, M. P. Acta Mater. 2014, 62, 1-48. doi:10.1016/j.actamat.2013.07.037

51. Wang, Z. B.; Lu, K.; Wilde, G.; Divinski, S. V. Scr. Mater. 2011, 64, 1055-1058. doi:10.1016/j.scriptamat.2011.02.018

52. Wang, Z. B.; Lu, K.; Wilde, G.; Divinski, S. Appl. Phys. Lett. 2008, 93 , 131904. doi:10.1063/1.2992628

53. Minkwitz, C.; Herzig, C.; Rabkin, E.; Gust, W. Acta Mater. 1999, 47, 1231-1239. doi:10.1016/S1359-6454(98)00429-7

54. Monzen, R.; Sumi, Y.; Kitagawa, K.; Mori, T. Acta Metall. Mater. 1990, 38, 2553-2560. doi:10.1016/0956-7151(90)90266-J

55. Borisov, V. T.; Golikov, V. M.; Scherbedinskiy, G. V. Phys. Met. Metallogr. 1964, 17, 10.

56. Divinski, S.; Ribbe, J.; Schmitz, G.; Herzig, C. Acta Mater. 2007, 55, 3337-3346. doi:10.1016/j.actamat.2007.01.032

57. Howe, J. M. Interfaces in Materials; Wiley: New York, NY, U.S.A., 1997.

58. Kidson, G. V. J. Nucl. Mater. 1961, 3, 21-29. doi:10.1016/0022-3115(61)90175-1

59. Charlot, F.; Gaffet, E.; Zeghmati, B.; Bernard, F.; Niepce, J. C. Mater. Sci. Eng., A 1999, 262, 279-288. doi:10.1016/S0921-5093(98)01017-X

60. Wiecinski, P.; Garbacz, H.; Murakami, H.; Kurzydlowski, K. J. Phys. Status Solidi C 2010, 7, 1395-1398. doi:10.1002/pssc.200983399

61. Wang, H. L.; Wang, Z. B.; Lu, K. Acta Mater. 2012, 60, 1762-1770. doi:10.1016/j.actamat.2011.12.016

62. Tong, W. P.; Tao, N. R.; Wang, Z. B.; Lu, J.; Lu, K. Science 2003, 299, 686-688. doi:10.1126/science.1080216

63. Tong, W. P.; Tao, N. R.; Wang, Z. B.; Zhang, H. W.; Lu, J.; Lu, K. Scr. Mater. 2004, 50, 647-650. doi:10.1016/j.scriptamat.2003.11.022

64. Porter, D.; Easterling, K. Phase Transformation in Metals and Alloys, 2nd ed.; Chapman \& Hall: London, United Kingdom, 1992.

65. Katona, G. L.; Vladymyrskyi, I. A.; Makogon, I. M.; Sidorenko, S. I.; Kristaly, F.; Daróczi, L.; Csik, A.; Liebig, A.; Beddies, G.; Albrecht, M.; Beke, D. L. Appl. Phys. A 2014, 115, 203-211. doi:10.1007/s00339-013-7949-z 
66. Embury, J. D.; Deschamps, A.; Brechet, Y. Scr. Mater. 2003, 49, 927-932. doi:10.1016/S1359-6462(03)00479-2

67. Fecht, H. J. Nanophase materials by mechanical attrition: synthesis and characterization. In Nanophase materials: synthesis-properties-applications; Hadjipanayis, G. C.; Siegel, R. W., Eds.; NATO ASI Series, Vol. 260; Kluwer: Amsterdam, Netherlands, 1994; pp 125-144. doi:10.1007/978-94-011-1076-1_18

68. Reumont, G.; Perrot, P.; Fiorani, J. M.; Hertz, J. J. Phase Equilib. 2000, 21, 371-378. doi:10.1361/105497100770339905

69. Lehrer, E. Z. Elektrochem. Angew. Phys. Chem. 1930, 36, 383-392.

70. Tong, W. P.; Han, Z.; Wang, L. M.; Lu, J.; Lu, K. Surf. Coat. Technol. 2008, 202, 4957-4963. doi:10.1016/j.surfcoat.2008.04.085

71. Yang, H. P.; Wu, X. C.; Min, Y. A.; Wu, T. R.; Gui, J. Z. Surf. Coat. Technol. 2013, 228, 229-233. doi:10.1016/j.surfcoat.2013.04.033

72. Balusamy, T.; Sankara Narayanan, T. S. N.; Ravichandran, K. Surf. Coat. Technol. 2012, 213, 221-228. doi:10.1016/j.surfcoat.2012.10.051

73. Balusamy, T.; Sankara Narayanan, T. S. N.; Ravichandran, K.; Park, I. S.; Lee, M. H. Surf. Coat. Technol. 2013, 232, 60-67. doi:10.1016/j.surfcoat.2013.04.053

74. Balusamy, T.; Sankara Narayanan, T. S. N.; Ravichandran, K.; Park, I. S.; Lee, M. H. Vacuum 2013, 97, 36-43. doi:10.1016/j.vacuum.2013.04.006

75. Yang, H.; Wu, X.; Yang, Z.; Pu, S.; Wang, H. J. Alloys Compd. 2014, 590, 388-395. doi:10.1016/j.jallcom.2013.12.151

76. Sun, H. Q.; Shi, Y. N.; Zhang, M.-X.; Lu, K. Surf. Coat. Technol. 2008, 202, 3947-3953. doi:10.1016/j.surfcoat.2008.02.010

77. Xiang, Z. D.; Datta, P. K. Scr. Mater. 2006, 55, 1151-1154. doi:10.1016/j.scriptamat.2006.08.016

78. Si, X.; Lu, B. N.; Wang, Z. B. J. Mater. Sci. Technol. 2009, 25, 433-436.

79. Gu, J. F.; Bei, D. H.; Pan, J. S.; Lu, J.; Lu, K. Mater. Lett. 2002, 55, 340-343. doi:10.1016/S0167-577X(02)00389-0

80. Balusamy, T.; Sankara Narayanan, T. S. N.; Ravichandran, K.; Park, I. S.; Lee, M. H. Mater. Charact. 2013, 85, 38-47. doi:10.1016/j.matchar.2013.08.009

81. Zhang, H. W.; Wang, L.; Hei, Z. K.; Liu, G.; Lu, J.; Lu, K. Z. Metallkd. 2003, 94, 1143-1147. doi:10.3139/146.031143

82. Lin, Y.; Lu, J.; Wang, L.; Xu, T.; Xue, Q. Acta Mater. 2006, 54, 5599-5605. doi:10.1016/j.actamat.2006.08.014

83. Farokhzadeh, K.; Qian, J.; Edrisy, A. Mater. Sci. Eng., A 2014, 589, 199-208. doi:10.1016/j.msea.2013.09.077

84. Ge, L.; Tian, N.; Lu, Z.; You, C. Appl. Surf. Sci. 2013, 286, 412-416. doi:10.1016/j.apsusc.2013.09.105

85. Sun, J.; Tong, W. P.; Zuo, L.; Wang, Z. B. Mater. Des. 2013, 47, 408-415. doi:10.1016/j.matdes.2012.11.029

86. Zhan, Z.; He, Y.; Wang, D.; Gao, W. Intermetallics 2006, 14, 75-81. doi:10.1016/j.intermet.2005.04.019

87. Zhan, Z.; He, Y.; Wang, D.; Gao, W. Oxid. Met. 2007, 68, 243-251. doi:10.1007/s11085-007-9073-y

88. Straumal, B.; Korneva, A.; Zięba, P. Arch. Civil Mech. Eng. 2014, 14, 242-249. doi:10.1016/j.acme.2013.07.002

89. Straumal, B. B.; Pontikis, V.; Kilmametov, A. R.; Mazilkin, A. A.; Dobatkin, S. V.; Baretzky, B. Acta Mater. 2017, 122, 60-71. doi:10.1016/j.actamat.2016.09.024

90. Guo, S.; Wang, Z. B.; Wang, L. M.; Lu, K. Surf. Coat. Technol. 2014, 258, 329-336. doi:10.1016/j.surfcoat.2014.09.005

91. Guo, S.; Wang, Z. B.; Lu, K. J. Mater. Sci. Technol. 2015, 31, 1268-1273. doi:10.1016/j.jmst.2015.09.015
92. Liang, Y. L.; Wang, Z. B.; Zhang, J.; Zhang, J. B.; Lu, K. Appl. Surf. Sci. 2016, 385, 341-348. doi:10.1016/j.apsusc.2016.05.142

93. Fu, T.; Zhou, Z. F.; Zhou, Y. M.; Zhu, X. D.; Zeng, Q. F.; Wang, C. P.; Li, K. Y.; Lu, J. Surf. Coat. Technol. 2012, 207, 555-564. doi:10.1016/j.surfcoat.2012.07.076

94. Wen, M.; Gu, J.-F.; Liu, G.; Wang, Z.-B.; Lu, J. Surf. Coat. Technol. 2007, 201, 6285-6289. doi:10.1016/j.surfcoat.2006.11.031

95. Wen, M.; Gu, J.-F.; Liu, G.; Wang, Z.-B.; Lu, J. Appl. Surf. Sci. 2008, 254, 2905-2910. doi:10.1016/j.apsusc.2007.10.035

96. Lu, Y. H.; Wang, Z. B.; Song, Y. Y.; Rong, L. J. Corros. Sci. 2016, 102, 301-309. doi:10.1016/j.corsci.2015.10.021

97. Konstantinović, M. J.; Bonny, G. Acta Mater. 2015, 85, 107-111. doi:10.1016/j.actamat.2014.11.026

98. Liu, X. C.; Zhang, H. W.; Lu, K. Science 2013, 342, 337-340. doi:10.1126/science.1242578

99. Liu, X. C.; Zhang, H. W.; Lu, K. Scr. Mater. 2015, 95, 54-57. doi:10.1016/j.scriptamat.2014.10.003

\section{License and Terms}

This is an Open Access article under the terms of the Creative Commons Attribution License (http://creativecommons.org/licenses/by/4.0), which permits unrestricted use, distribution, and reproduction in any medium, provided the original work is properly cited.

The license is subject to the Beilstein Journal of

Nanotechnology terms and conditions:

(http://www.beilstein-journals.org/bjnano)

The definitive version of this article is the electronic one which can be found at: $\underline{\text { doi: } 10.3762 / \text { bjnano.8.59 }}$ 